\title{
Potato (Solanum tuberosum L.) and Sulla (Hedysarum coronarium L.) Intercropping in Tunisia: Effects in Water Consumption and Water Use Efficiency
}

\author{
Mourad. Rezig ${ }^{1}$, Ali. Sahli ${ }^{2}$, Faycel. Ben jeddi ${ }^{2} \&$ Youssef. Harbaoui ${ }^{2}$ \\ ${ }^{1}$ Institut National de Recherches en Génie Rural Eaux et Forêts, Tunisie \\ ${ }^{2}$ Institut National Agronomique de Tunisie, Tunis, Tunisie \\ Correspondance: Mourad Rezig, Institut National de Recherches en Génie Rural Eaux et Forêts, Rue Hédi \\ Elkarray, Ariana, Tunisie. Tel: 216-98-576 500. E-mail: rezigue_mourad@yahoo.fr \\ Ali Sahli, Institut National Agronomique de Tunisie, L.R. Sciences Horticoles, Université de Carthage, 43 \\ Avenue Charles Nicolle 1082 cité Mahrajène Tunis, Tunisie. Tel: 216-25-134-331. E-mail: \\ sahli_inat_tn@yahoo.fr
}

Received: June 21, 2013 Accepted: July 19, 2013 Online Published: September 15, 2013

doi:10.5539/jas.v5n10p123 URL: http://dx.doi.org/10.5539/jas.v5n10p123

\begin{abstract}
This experiment was carried out at the Technical Center of Potato (C.T.P) situated in the low valley of Medjerda river at Tunisia, during two growing seasons (2006-2007) and (2008-2009). It aims at evaluating the effect of intercropping potato (Solanum tuberosum cv. Spunta) and sulla (Hedysarum coronarium L. cv. Bikra 21) grown under 1:1 intercropping row arrangement and sole cropping on water consumption and water use efficiency of one potato variety and one sulla variety. In addition, land equivalent ratio (LER) was determined to assess the efficiency of the intercropping system. Intercropping had no significant effect on the above parameters and tuber dry biomass production of potato and sulla. However, it increased the total dry biomass of the intercropping system. This increase occurred during the two cultivating seasons of 2007 and 2009 respectively from 12.5 to $14.8 \%$ compared to the potato in sole cropping. Intercropping has led to a similar reduction of water consumption (WC) of both crops. This reduction was 36 and $28 \%$ for 2007 and 2009 seasons respectively and for both crops. However, intercropping has led to an increase in the overall (WC) of the mixed system by 9.1 and $13.8 \%$ in 2007 and 2009 respectively. Water Use Efficiency (WUE) has been improved from 35.4 to $45.6 \%$ for potato in sole intercropping and from 25 to $37.5 \%$ for sulla intercropped. The values of total LER were higher than one, which indicates the superiority of intercropping system over the sole cropping system.
\end{abstract}

Keywords: sulla, potato, intercropping system, water consumption, water use efficiency

Abbreviation: AGDM-Above-Ground Dry Matter; GDD-Growing Degree days; LER-Land Equivalent Ratio; TDM-Total Dry Matter; TUBDM-Tuber Dry Matter; WC-Water Consumption; WUE-Water Use Efficiency

\section{Introduction}

Increasing crops productivity and saving irrigation water are two interrelated issues raising a lot of concern these days in Tunisia. For the arid and semi-arid areas of the world, water use is of great importance in determining resource utilization in intercropping systems. Ogindo and Walker (2005) confirmed that under intercropping, crops conserve water largely because of early high leaf area index and higher leaf area. In intercropping, agricultural income, nutrient, water and radiation resources may be used more effectively than in sole cropping (Willey, 1990; Rodrigo et al., 2001). Intercropping has been reported to reduce water evaporation, and improve conservation of the soil moisture compared with sole cropping (Ghanbari et al., 2010). Usually, complementary use of resources occurs when the component species of an intercrop use qualitatively different resources or they use the same resources at different places or at different times (Tofinga et al., 1993). Therefore, crops selection that differs in competitive ability in time or space is essential for an efficient intercropping system. Due to these issues, numerous research based in indirect measurements of water consumption by intercrop reported an increased water use efficiency in this system (Reddy \& Willey, 1981; Mandal et al., 1996; Walker \& Ogindo, 2003). Nevertheless, it is very difficult to separate the water use by two crops during the co-growth period (Adiku et al., 2001; Morris \& Garrity, 1993). Morris and Garrity (1993) report no significant differences in total water uptake between intercrops 
and sole crops, but WUE by intercrops was higher from 18 to $99 \%$ than in sole crops. Furthermore, the biological basis for intercropping involves complementarily of resources used by the two crops (Barhom, 2001). Morris and Garrity (1993) declared that water capture by intercrops is higher by 7\% than sole cropping. Moreover, water use efficiency was the highest under soybean-maize intercropping, compared to sole maize and sole soybean (Barhom, 2001). Similarly, Natarajan and Willey (1980a, b) found no difference in water use between monocrops and intercrops of pigeonpea and sorghum up to the point when the shorter duration sorghum was harvested. Reddy and Willey (1981) showed that water use by millet-groundnut intercrops exceeded that of the monocrops, mainly because a larger leaf area index was maintained for longer. Many studies have been conducted in potato for water consumption and water use efficiency in different regions under sole cropping (Yactayo et al., 2013; Badr et al., 2012; Ati et al., 2012) and sole intercropping (Bharati et al., 2007; Sharaiha \& Hadidi, 2008; Rezig et al., 2010). However, hardly any information about water consumption and water use efficiency of potato and sulla crops in intercropping system has been reported. Therefore, the objective of this study was to investigate water consumption and water use efficiency of potato and sulla in sole intercropping with respective sole cropping, considering the changes with growth years.

\section{Materials and Methods}

\subsection{Experimental Site}

The experiment was carried out at the Technical Centre of Potato (C.T.P) situated in the low valley of Medjerda river at Saida, Tunisia $\left(10^{\circ} \mathrm{E}, 37^{\circ} \mathrm{N}\right.$, Alt. $\left.328 \mathrm{~m}\right)$, during two growing seasons (2006-2007) and (2008-2009) under semi-arid conditions. The annual average rainfall is about $450 \mathrm{~mm}$, distributed irregularly mostly from December to April. The soil had a clay-loam texture with $180 \mathrm{~mm} \mathrm{~m}^{-1}$ total available water and $2000 \mathrm{mg} \mathrm{l}^{-1}$ water salinity. The bulk density varied from 1.34 to 1.60 in from the surface to the depth (Rezig et al., 2010).

\subsection{Plant Material}

Plant material consisted of one potato variety (Solanum tuberosum cv. Spunta) and one sulla variety (Hedysarum coronarium L. cv. Bikra 21). In the first growing season (2006-2007), sulla seedlings were transplanted on December 21, 2006 (first growing season) and December 01, 2008 (second growing season) in a depth of 1.5 to $2 \mathrm{~cm}$. The plant density was 170000 plants $\mathrm{ha}^{-1}$. Potato tubers were transplanted on February 12,2007 (first growing season) and March 15, 2009 (second growing season) in a depth of 10 to $15 \mathrm{~cm}$. This date corresponds to the three leaves stage of sulla plants. Plant density for potato was 41667 tubers ha ${ }^{-1}$.

\subsection{Experimental Design}

Three experimental treatments were implemented, namely potato-sulla intercropping system (M1); potato sole cropping (M2) and sulla sole cropping (M4). An experimental plot of (M1) is composed of 5 rows of potato (M3) intercropped with 4 lines of sulla (M5). An experimental plot of (M2) is composed of 5 rows spaced $80 \mathrm{~cm}$ with $30 \mathrm{~cm}$ spacing within the line and an experimental plot of (M4) is made up of 9 rows spaced of $40 \mathrm{~cm}$ (Figure 1). The adopted experimental design was that of randomized complete blocks with three replications. Every experimental plot had $10 \mathrm{~m}$ length and $4.8 \mathrm{~m}$ width.
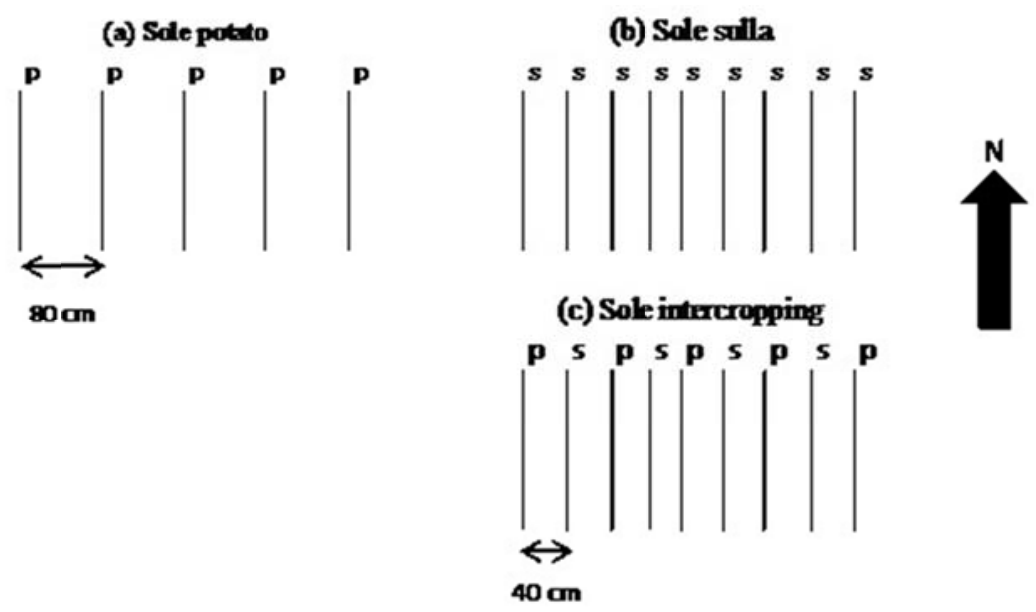

Figure 1. Experimental plot: sole potato (a); sole sulla (b) and sole intercropping potato and sulla (c) 


\subsection{Field Measurements}

2.4.1 Leaf area Index (LAI), Above-Ground Dry Matter (AGDM), Tuber Dry Matter (TUBDM) and Total Dry Matter Production (TDM)

The observations were made on leaf area index, above-ground dry matter, tuber dry matter and total dry matter $\left(\mathrm{g} \mathrm{m}^{-2}\right)$. Plants were harvested for growth analysis at 52, 56, 62, 69, 75, 83, 90, 96, 103, 111 DAP (potato) and $110,114,120,127,133,141$ DAS (sulla) in (2006-2007) and at 48, 55, 62, 71, 76, 83, 90, 104, 118 DAP (potato) and $107,115,122,129,138$ and 143 DAS (sulla) in (2008-2009). At each sampling, three plants by plot (potato and/or sulla) were collected. After separation of the plant organs, leaf area and fresh weight were measured. The weightings were made using a precision balance (Sartorius, Model PB3001). Leaf area was measured using a LICOR LI 3100 leaf-area meter then all material was dried at $65^{\circ} \mathrm{C}$ to constant weight.

\subsubsection{Growing Degree Days (GDD)}

Growing degree days (GDD), based on air temperatures were used as the explanatory variable in the regression analysis (AGDM, TUBDM and WUE) and accumulated from the date of planting. For each day, GDD was calculated according to the following formula:

$$
\mathrm{GDD}=\frac{(\mathrm{Tmax}+\mathrm{Tmin})}{(\mathrm{Tmin})}-\mathrm{Tb}
$$

Where Tmax and Tmin are daily maximum and minimum air temperature, respectively, and $\mathrm{Tb}$ is the base temperature. A base temperature $(\mathrm{Tb})$ of $5^{\circ} \mathrm{C}$ was used as the minimum temperature for sulla growth (Ben Jeddi, 2005 ) and the $\mathrm{Tb}$ for potato was equal to $7^{\circ} \mathrm{C}$ (Sands et al., 1979).

\subsection{Theoretical Formulations}

\subsubsection{Crop Coefficient}

According to the FAO-56 method (Allen et al., 1998), Ea in sole cropping is modeled as:

$$
\mathrm{Ea}=\mathrm{Kc} * \mathrm{Ks} * \mathrm{Ep}
$$

Where $\mathrm{Kc}$ is the crop coefficient under adequate soil moisture (unitless), Ks is the soil moisture coefficient (0-1, unitless), and Ep is the potential evapotranspiration for a reference grass in $\mathrm{mm} \mathrm{d}^{-1}, \mathrm{KcKs}$ is the combined crop coefficient and includes the effect of both crop type and soil moisture stress. Soil moisture stress is indicated when Ks is less than 1.0 (Allen et al., 1998).

In intercropping when the fractions of ground covered by each crop are different, the $\mathrm{K}_{\mathrm{C}}$ for an intercropped field can be estimated by weighting the $\mathrm{K}_{\mathrm{C}}$ values for the individual crops according to the fraction of area covered by each crop and by the height of the crop:

In the FAO-56 method (Allen et al., 1998), crop coefficient in intercropping $\left(\mathrm{Kc}_{\text {intercrop }}\right)$ is modeled as:

$$
\text { Kc intercropping }=\frac{((\mathrm{F} 1 * \mathrm{H} 1 * \mathrm{Kc} 1)+(\mathrm{F} 2 * \mathrm{H} 2 * \mathrm{Kc} 2))}{((\mathrm{F} 1 * \mathrm{H} 1)+(\mathrm{F} 2 * \mathrm{H} 2))}
$$

Where F1 and F2 are respectively the fractions of ground covered by the potato and sulla, H1 and H2 are respectively the heights of potato and sulla, and $\mathrm{KC} 1$ and $\mathrm{KC} 2$ are the $\mathrm{KC}$ values for potato and sulla.

Thus, the crop coefficient of potato and sulla in the sole intercropping is

$$
\begin{aligned}
& \text { Kc potato intercropping }=\frac{(\text { FPDT*HPDT } * \text { KcPDT })}{((\text { FPDT } * \text { HPDT })+(\text { FSulla } * \text { HSulla }))} \\
& \text { Kc sulla intercropping }=\frac{((\text { FSulla } * \text { HSulla } * \text { KcSulla })}{((\text { FPDT } * \text { HPDT })+(\text { FSulla } * \text { HSulla }))}
\end{aligned}
$$

\subsubsection{Reference Evapotranspiration}

The climate data used to calculate $\mathrm{ET}_{0}$ were obtained from a weather station at the experimental site, including maximum temperature (Tmax), minimum temperature (Tmin), Relative humidity $(\mathrm{H})$, wind speed (u2) and sunshine (h) during two growing seasons (2006-2007 and 2008-2009). Reference evapotranspiration (ET E $_{0}$ ) was estimated by the MABIA-ETo software (Jabloun and Sahli, 2008) using the FAO-Penman-Monteith approach (Allen et al., 1998).

\subsubsection{Water Consumption (WC)}

Water consumption was estimated with soil water balance equation as follows (Hillel, 1998):

$$
\mathrm{WC}=\mathrm{P}+\mathrm{I}+\mathrm{U}+\mathrm{R}-\mathrm{DW}-\Delta \mathrm{S}
$$


Where $\mathrm{P}$ is the effective precipitation $(\mathrm{mm})$, I the irrigation $(\mathrm{mm}), \mathrm{U}$ the upward capillary flow into the root zone (mm), R the runoff $(\mathrm{mm})$, DW the downward drainage out the root zone $(\mathrm{mm})$ and $\Delta \mathrm{S}$ the change of soil water stored in soil layer of 0-80 cm (mm). The upward and downward flow was estimated using Darcy's law (Kar et al., 2007; De Medeiros et al., 2005). Results indicated that these two parameters were insignificant at the experimental site. Runoff was also insignificant during the two growing seasons. Soil water content was measured once a week with neutron probe (Brand Nardeux, Model Solo 25). Soil water content data were collected for every $10 \mathrm{~cm}$ intervals in a soil profile of $10-80 \mathrm{~cm}$. Soil water content of soil layer of $0-20 \mathrm{~cm}$ was measured gravimetrically. Some measurements were added before and after irrigation and heavy rain events. Neutron probe access tubes were placed in sole cropping (potato and sulla) at the center of two rows, and in sole intercropping at the center of potato and sulla rows.

\subsubsection{Water Use Efficiency (WUE) and Land Equivalent Ratio (LER)}

WUE in sole cropping (potato and sulla) was calculated using the following equation:

$$
\mathrm{WUE}=\frac{\mathrm{TDM}}{\mathrm{WC}}
$$

Where WUE is the water use efficiency $\left(\mathrm{kg} \mathrm{m}^{-3}\right)$, TDM the total dry matter production $(\mathrm{kg})$, and WC is the total water consumption over the whole growing season $(\mathrm{mm})$.

WUE in sulla sole intercropping was calculated using the following equation:

$$
\begin{gathered}
\text { WUE sulla }- \text { intercrop }=\frac{\text { TDM }}{(\text { Fwater-Sulla-intercrop }) * W C} \\
\text { Fwater }- \text { sulla }- \text { intercrop }=\frac{\text { WCSulla-intercrop }}{\text { WC }}
\end{gathered}
$$

WUE in potato sole intercropping was calculated using the following equation:

$$
\begin{gathered}
\text { WUE Potato }- \text { intercrop }=\frac{\text { TDM }}{(\text { Fwater-potato-intercrop }) * W C} \\
\text { Fwater - potato }- \text { intercrop }=\frac{\text { WCpotato-intercrop }}{\text { WC }}
\end{gathered}
$$

The intercropping advantage was assessed by calculating the land equivalent ratio (LER), an index of intercropping advantage and a reflection of the degree of interspecific competition or facilitation in an intercropping system. The formula is defined as follows (Vandermeer, 1992; Li et al., 1999; Fetene, 2003):

$$
\mathrm{LER}=\frac{\mathrm{YPI}}{\mathrm{YPM}}+\frac{\mathrm{YSI}}{\mathrm{YSM}}
$$

Where $Y_{P M}$ and $Y_{P I}$ are TDM of potato in sole cropping and intercropping $\left(\mathrm{kg} \mathrm{ha}^{-1}\right)$, respectively; $Y_{S M}$ and $Y_{S I}$ is TDM of sulla in sole cropping and intercropping, respectively $\left(\mathrm{kg} \mathrm{ha}^{-1}\right)$. An LER of 1.0 indicates that the two intercropped species have similar demands on the same limiting resources. An LER greater than 1.0 reveals an intercropping advantage or a demonstration that interspecific facilitation (or complementarity) is higher than interspecific competition so that intercropping results in greater land-use efficiency. An LER less than 1.0 reveals mutual antagonism in the intercropping system. Thus, an LER less than 1 has no intercropping advantage and indicates that interspecific competition is stronger than interspecific facilitation in the intercropping system (Wahla et al., 2009).

\subsection{Statistical Analysis}

The results were subjected to variance analysis of one factor by General Linear Model (GLM). This analysis was performed using SPSS 10.0 software. The ensemble was completed by multiple comparisons of means with Student Newman Keuls test (S-N-K).

\section{Results and Discussion}

\subsection{Dry Matter Production}

\subsubsection{Above Dry Matter (AGDM) of Potato and Sulla}

The variations of above-ground dry matter production of potato-sulla intercropping (M1), potato in sole cropping (M2) and potato in sole intercropping (M3), during the two cropping seasons 2006-2007 (a) and 2008-2009 (b) were shown in Figure 2. 

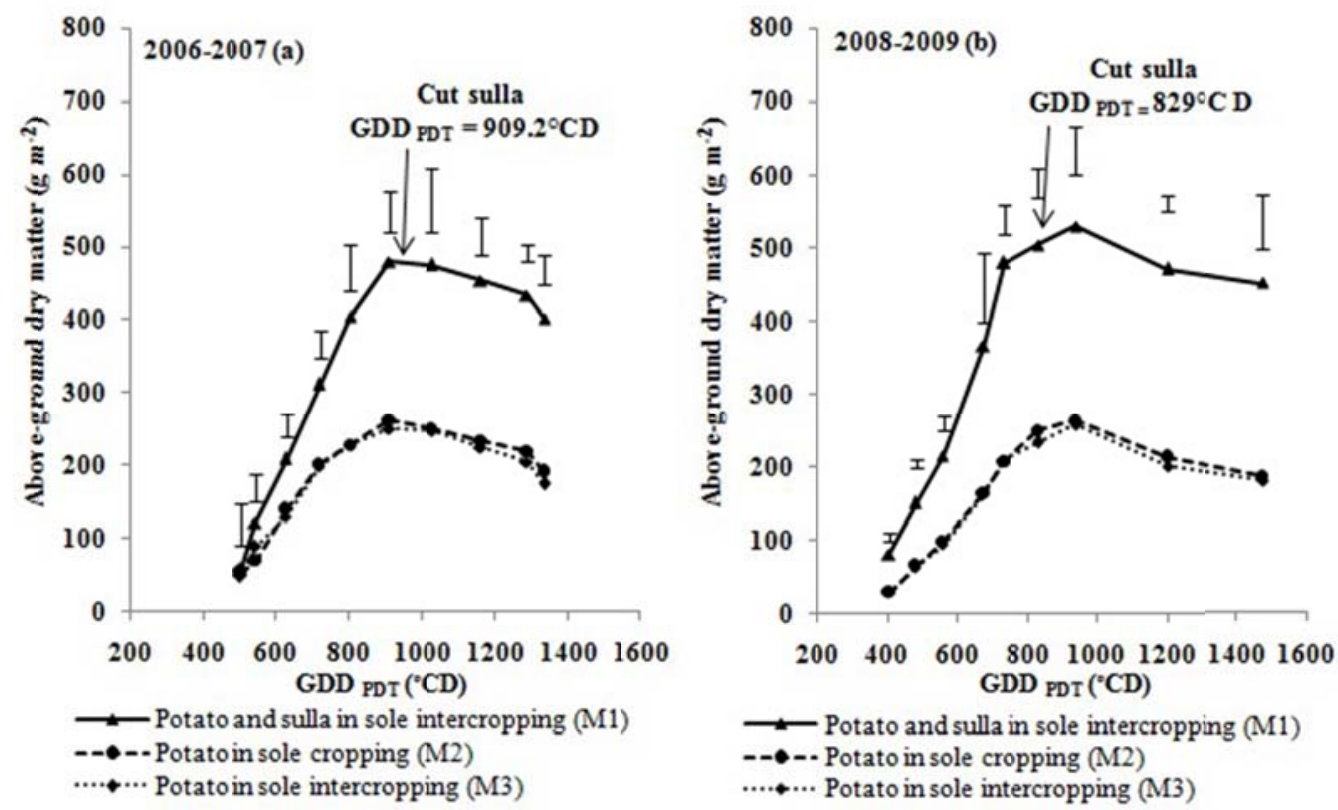

Figure 2. Above-ground dry matter of potato and sulla in sole intercropping (M1), potato in sole cropping (M2) and potato in sole intercropping (M3), during the two cropping seasons 2006-2007 (a) and 2008-2009 (b). The vertical bars represent the least significant difference at $5 \%$ (LSD)
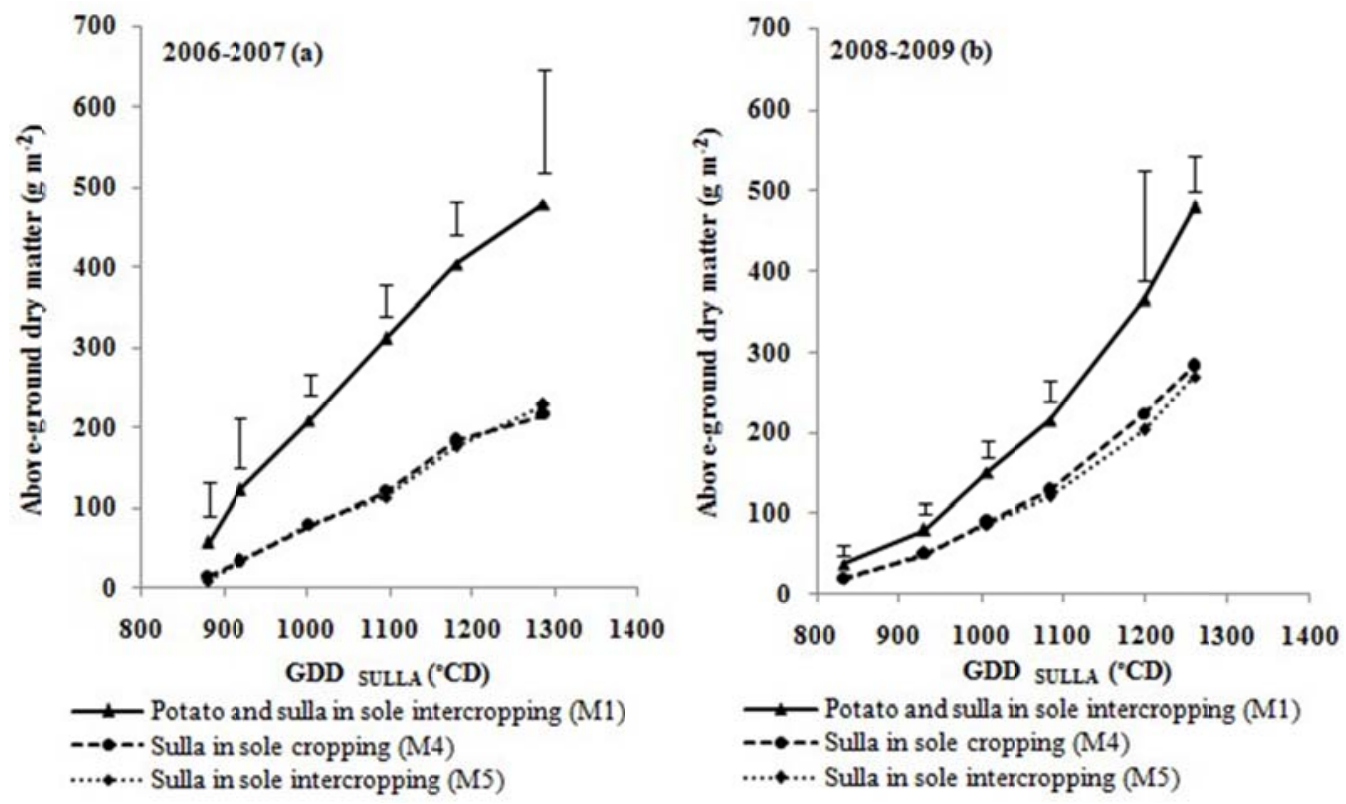

Figure 3. Above-ground dry matter of potato and sulla in sole intercropping (M1), sulla in sole cropping (M4) and sulla in sole intercropping (M5), during the two cropping seasons 2006-2007 (a) and 2008-2009 (b). The vertical bars represent the least significant difference at $5 \%$ (LSD)

Variance analysis showed that there was a significant effect $(\mathrm{P}<0.05)$ of intercropping on AGDM production. Moreover, the AGDM in M1 was significantly higher than in M2 and M4. So, the potato-sulla intercropping had the greatest AGDM production in the first experiment and it was equal to $479.1 \mathrm{~g} \mathrm{~m}^{-2}$. The same for the second experiment, and it was equivalent to $528.6 \mathrm{~g} \mathrm{~m}^{-2}$. For potato in sole cropping (M2) and in sole intercropping (M3), no significant differences $(\mathrm{P}>0.05)$ were found in the AGDM production. In fact, the AGDM production 
by potato in sole intercropping for the two experiments was respectively equal to 251.1 and $258.6 \mathrm{~g} \mathrm{~m}^{-2}$. Nevertheless, for potato in sole cropping the AGDM production has varied from 262.6 to $263.1 \mathrm{gm}^{-2}$.

Figure 3 showed the evolution of the AGDM of potato and sulla in sole intercropping (M1), sulla in sole cropping (M4) and sulla in sole intercropping (M5), during the two cropping seasons 2006-2007 (a) and 2008-2009 (b).

It has been noticed that no significant differences for sulla $(\mathrm{P}>0.05)$ were found between the AGDM production by M4 and M5. During the two cropping seasons 2006-2007 and 2008-2009, the AGDM production was equal to $\left(284 ; 269.9 \mathrm{~g} \mathrm{~m}^{-2}\right)$ in M5 and it was respectively equivalent to $\left(215.7 ; 228.1 \mathrm{~g} \mathrm{~m}^{-2}\right)$ in M4.

\subsubsection{Tuber Dry Matter Production (TUBDM)}

Tuber dry matter production by potato in sole cropping (M2) and by potato in sole intercropping (M3), during the two cropping seasons 2006-2007 (a) and 2008-2009 (b) was given in Figure 4.

Variance analysis showed that there was no significant effect $(\mathrm{P}>0.05)$ of intercropping on TUBDM production by potato in sole cropping (M2) and in sole intercropping (M3). In fact, for both experiments, the TUBDM production by $\mathrm{M} 3$ was respectively equal to $\left(1180.9 ; 1157.2 \mathrm{~g} \mathrm{~m}^{-2}\right)$ and it was respectively equivalent to (1213.9; $1220.8 \mathrm{~g} \mathrm{~m}^{-2}$ ) in $\mathrm{M} 2$.
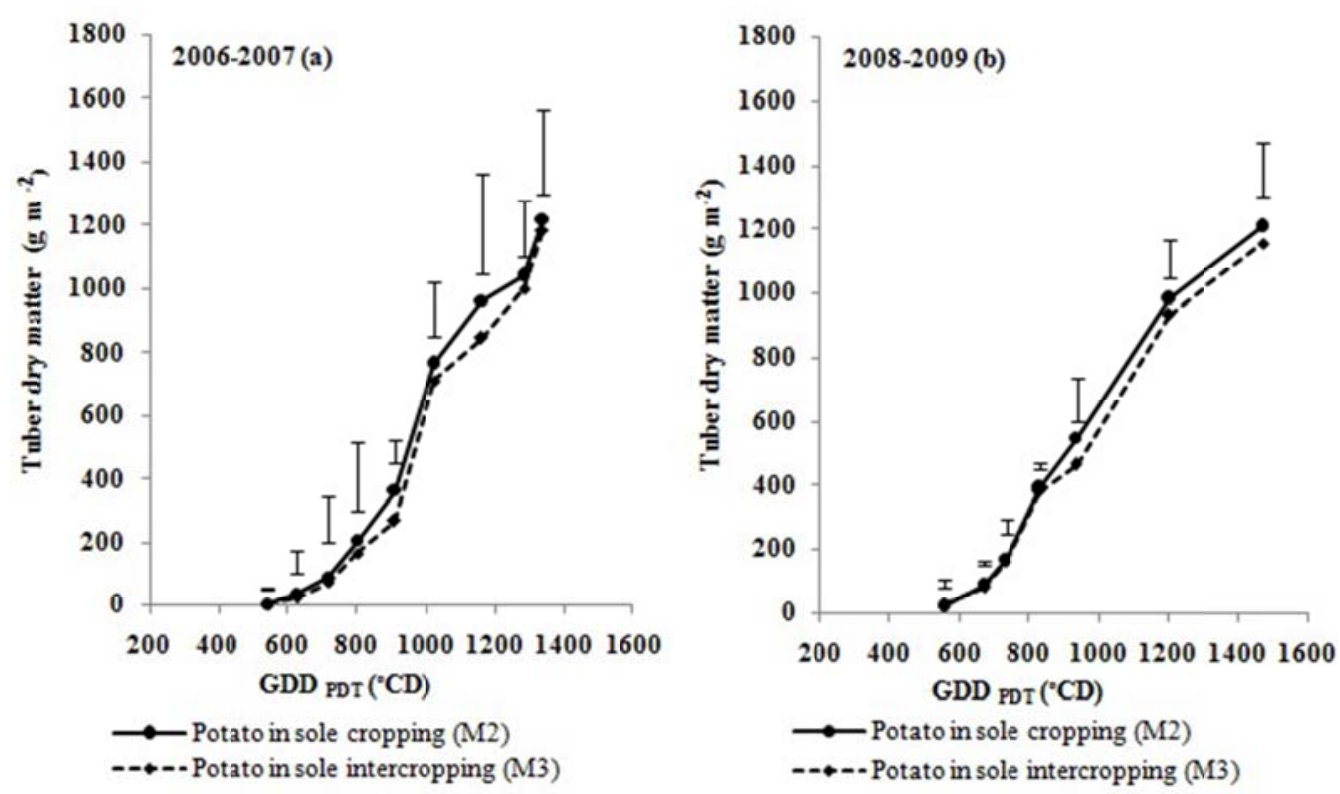

Figure 4. Tuber dry matter of potato in sole cropping (M2) and potato in sole intercropping (M3), during the two cropping seasons 2006-2007 (a) and 2008-2009 (b). The vertical bars represent the least significant difference at $5 \%$ (LSD)

\subsection{Water Consumption}

The Daily evolution of the water consumption (WC) by potato in sole cropping (M2) and potato in sole intercropping (M3), during the two cropping seasons of 2006-2007 (a) and 2008-2009 (b) was given in Figure 5. In fact, we observed that the daily WC by the two cropping systems (M2 and M3) varied through the years. In the first experiment, the daily WC by M2 was significantly higher than by M3. However, from the first cut of sulla $\left(52^{\text {nd }}\right.$ day after potato emergence) to the potato harvest, the daily WC by the two cropping systems was equal. Thus, throughout the development cycle of the potato, M2 has consumed $341 \mathrm{~mm}$, in part next to the M3 which has consumed only $217 \mathrm{~mm}$ that is a reduction of $36.4 \%$. Similarly, the results obtained during the second experiment were consistent with those of the first season. Indeed, during the early stages of the potato development, the daily WC by M2 was significantly higher than by M3. Nevertheless, from the first cut of sulla (48th day after potato emergence), the daily WC by M2 was equal to that by M3. Therefore, the total water consumption by M3 was $343.1 \mathrm{~mm}$ against to $246.1 \mathrm{~mm}$ by M2, which means a reduction of $27.7 \%$. 

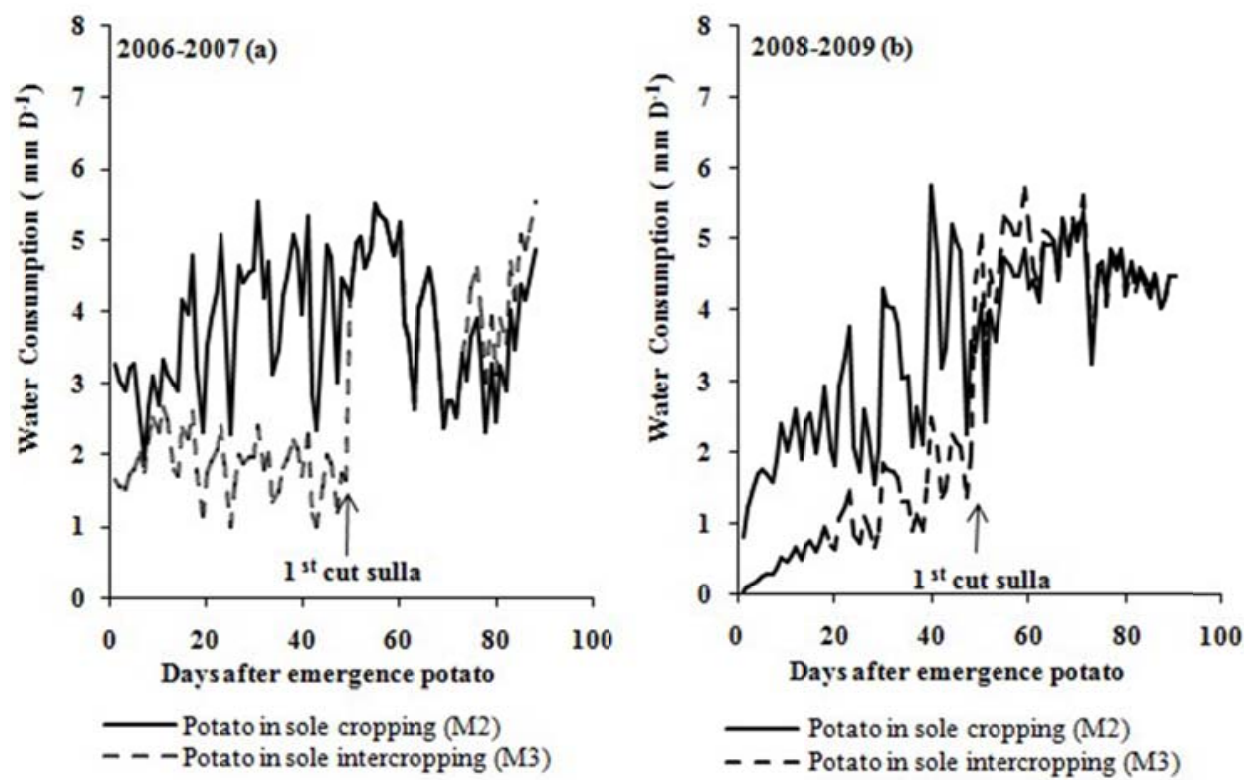

Figure 5. Daily water consumption of potato in sole cropping (M2) and potato in sole intercropping (M3), during the two cropping seasons 2006-2007 (a) and 2008-2009 (b)
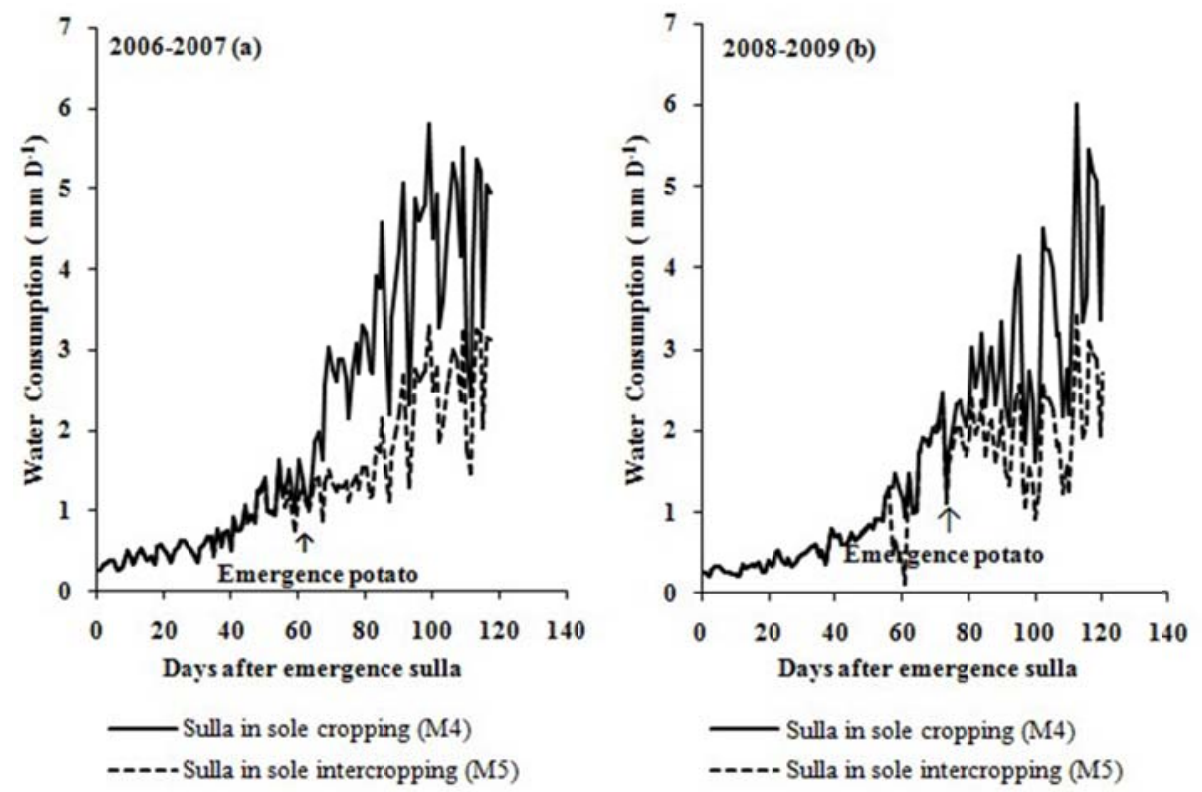

Figure 6. Daily water consumption of sulla in sole cropping (M4) and sulla in sole intercropping (M3), during the two cropping seasons 2006-2007 (a) and 2008-2009 (b)

Figure 6 showed the Daily evolution of the WC by sulla in sole cropping (M4) and by sulla in sole intercropping (M5), during the two growing seasons of 2006-2007 (a) and 2008-2009 (b). In fact, during the first campaign the curves illustrating the evolution of the daily WC follow the same pace. Yet, the daily WC by M5 becomes smaller than by the M4 at the potato emergence (coincides with the 62th day of sulla emergence). Thus, throughout the development cycle of sulla, the M4 has consumed $251.5 \mathrm{~mm}$, in part against the M5 has consumed only $160.4 \mathrm{~mm}$, which means a reduction of $36.2 \%$.

Similarly, for the second experiment, the WC by the two systems (M4) and (M5) appears to be identical to the 70th day of the sulla emergence. From that date, the daily WC by sulla in sole cropping becomes more important than in sole intercropping. Therefore, the total water consumption by M4 was $210.6 \mathrm{~mm}$ against to $152 \mathrm{~mm}$ by the M5, which means a reduction of $27.8 \%$. 


\subsection{Water Use Efficiency}

Water use efficiency (WUE) for total dry matter production by potato in sole cropping (M2) and by potato in sole intercropping (M3) during the two cropping seasons 2006-2007 (a) and 2008-2009 (b) was given in Figure 7. For the two growing seasons, the WUE obtained by potato in sole intercropping was significantly $(\mathrm{P}<0.05)$ higher than that marked by potato in sole cropping. Indeed, the WUE of M2 has varied respectively from 0.6 to $4.2 \mathrm{~kg} \mathrm{~m}^{-3}$ in (2006-2007) and from 0.7 to $4.3 \mathrm{~kg} \mathrm{~m}^{-3}$ (2008-2009). However, for M3 the WUE has respectively varied from 1.3 to $6.5 \mathrm{~kg} \mathrm{~m}^{-3}$ in (2006-2007) and from 4.6 to $7.9 \mathrm{~kg} \mathrm{~m}^{-3}$ (2008 -2009), which means an increase respectively for both experiments equal to 35.4 and $45.6 \%$. This increase in the WUE by potato in sole intercropping can be explained by the reduction in water consumption with no significant $(\mathrm{P}>0.05)$ effect of intercropping on the total dry matter production. Figure 8 showed the Water use efficiency (WUE) for total dry matter production by sulla in sole cropping (M4) and by sulla in sole intercropping (M5), during the two cropping seasons 2006-2007 (a) and 2008-2009 (b). Likewise for sulla, at the end of the development cycle and during the two experiments, the WUE obtained in sole intercropping was significantly $(\mathrm{P}<0.05)$ higher than that marked in sole cropping. The WUE of sulla in sole cropping has ranged, respectively, from 0.1 to $1.0 \mathrm{~kg} \mathrm{~m}^{-3}$ in (2006-2007) and from 0.3 to $1.5 \mathrm{~kg} \mathrm{~m}^{-3}$ (2008-2009). Moreover, those obtained by sulla intercropped have varied respectively, from 0.1 to $1.6 \mathrm{~kg} \mathrm{~m}^{-3}$ in (2006-2007) and from 0.3 to $2 \mathrm{~kg} \mathrm{~m}^{-3}$ in (2008-2009), which means an increase that vary from $25 \%$ to $37.5 \%$. This increase in the WUE by the intercropped sulla was due to the reduction in water consumption without any significant $(\mathrm{P}>0.05)$ effect of intercropping on the total dry matter production.

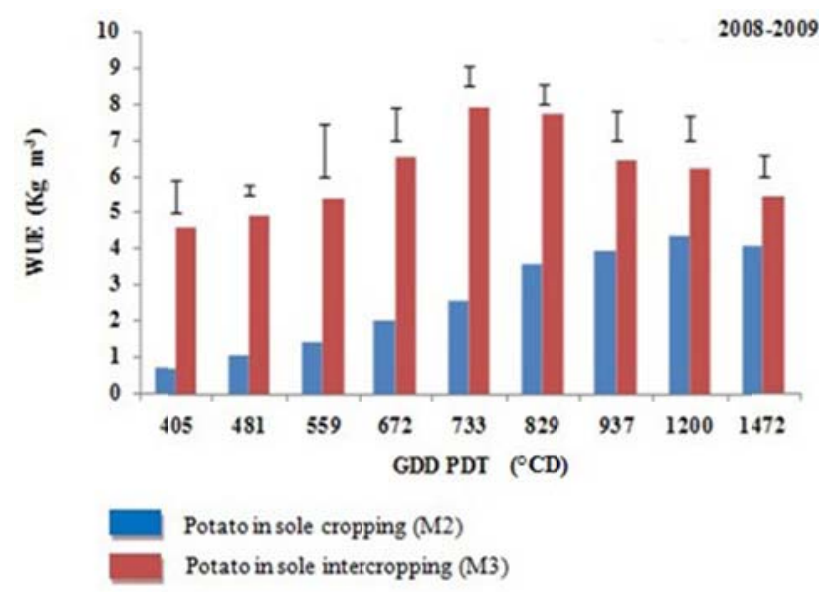

Figure 7. Water Use Efficiency of potato in sole cropping (M2) and potato in sole intercropping (M3), during the two cropping seasons 2006-2007 and 2008-2009. The vertical bars represent the least significant difference at 5\% (LSD)

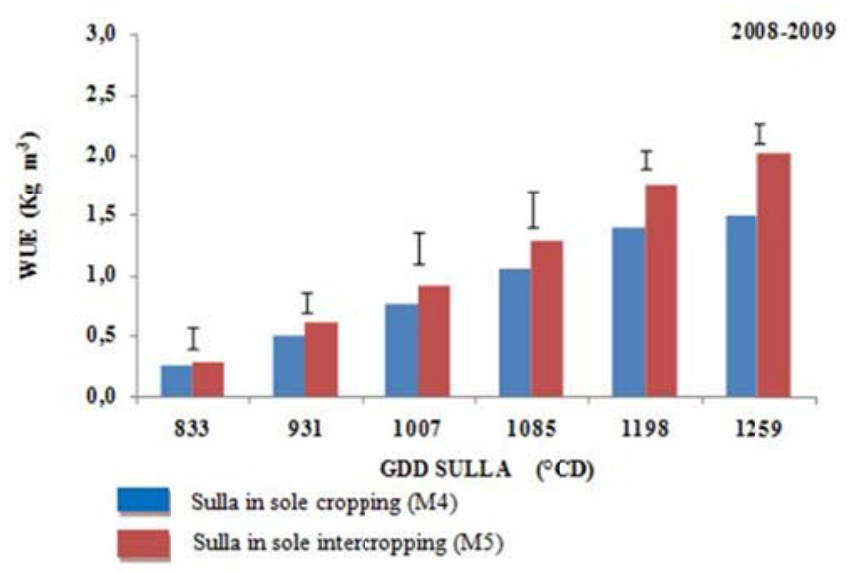

Figure 8. Water Use Efficiency of Sulla in sole cropping (M4) and Sulla in sole intercropping (M5), during the two cropping seasons 2006-2007 and 2008-2009. The vertical bars represent the least significant difference at 5\% (LSD) 


\subsection{Effect of Intercropping Potato-Sulla on Production}

In order to identify the effect of intercropping potato-sulla on production, we calculated the potato tuber fresh matter production (TUBFM) and sulla above-ground fresh matter production (AGFM).

Similarly, the economic advantage of the intercropping system has been calculated on the basis of LER. The results obtained during the two measurement campaigns (2006-2007) and (2008-2009) were represented in Table 1.

The results (Table 1) showed that for the potato in sole cropping (M2), the TUBFM has respectively varied for the two measurement campaigns (2006-2007) and (2008-2009) from 59.5 to $60.6 \mathrm{tha}^{-1}$. In sole intercropping (M3), the TUBFM was respectively equal to 59.1 and $57.8 \mathrm{t} \mathrm{ha}^{-1}$ for the both experiments. However, statistical analysis showed no significant differences $(\mathrm{P}>0.05)$ in TUBFM between M2 and M3. Besides, the intercropped sulla provided an additional forage production, with AGFM production estimated respectively for the two campaigns equivalent to 19.3 and $22.9 \mathrm{t} \mathrm{ha}^{-1}$ (Table 1). Similarly, during the two growing seasons the total LER of intercropping system potato-sulla has varied from 1.5 in (2006-2007) to 1.4 in (2008-2009). Moreover, the values of total (LER) were higher than one, which indicates the superiority of intercropping system over the sole cropping system.

Table 1. Yield of fresh matter (Tuber PDT and above-ground sulla) and LER

\begin{tabular}{|c|c|c|c|c|c|c|c|c|c|}
\hline \multirow[t]{3}{*}{ Season } & \multicolumn{3}{|c|}{ Potato } & \multicolumn{3}{|c|}{ Sulla } & \multicolumn{3}{|c|}{ LER } \\
\hline & \multicolumn{3}{|c|}{ TUBFM } & \multicolumn{2}{|c|}{ AFM } & \multirow[t]{2}{*}{ LSD } & \multicolumn{2}{|c|}{ Partial } & Total \\
\hline & M2 & M3 & & M4 & M5 & & PDT & SULLA & \\
\hline $2006-2007$ & $59,5 \mathrm{a}$ & $59,1 \mathrm{a}$ & 3,4 & $39,9 \mathrm{a}$ & $19,3 \mathrm{~b}$ & 13,0 & 1,0 & 0,5 & 1,5 \\
\hline $2008-2009$ & $60,6 \mathrm{a}$ & $57,8 \mathrm{a}$ & 4,8 & $48,2 \mathrm{a}$ & $22,9 \mathrm{~b}$ & 5,6 & 1,0 & 0,5 & 1,4 \\
\hline
\end{tabular}

TUBFM is the tuber fresh matter of potato; AFM is the above-ground fresh matter of sulla; LER is the Land Equivalent Ratio and LSD is the least significant difference at $5 \%$.

\section{Discussion}

Results of both experiments showed that the AGDM and the TUBDM production by the intercrop potato and sulla were not affected by this association. Thus, it had increased the AGDM and the TUBDM of the intercropping system. These results are consistent with several researchers who have reported that the above ground dry matter production by intercropping system was higher than in sole cropping (Hauggaard-Nielsen et al, 2001; Thorsted et al, 2006; Gao et al., 2009). Similarly, Bouwe et al. (2000) found that in intercropping system potato-beans, the yield of potato was not significantly different from that in sole cropping. This was due to the fact that the photosynthetic assimilation of potato plants was not hampered by the bean plants. Consequently, there was an increase of $9 \%$ in tuber yield per plant of potato in sole intercropping compared to potato sole cropping. The intercropping system potato-sulla has reduced the water consumption (WC) by potato and sulla in sole intercropping compared to that in sole cropping. This reduction has varied during the two experiments (2007 and 2009) from 36 to $27.8 \%$. However, it has increased the total WC by the intercropping system. This increase has also varied from $9.1 \%$ in 2007 to $13.8 \%$ in 2009 .

According to Morris and Garrity (1993), the total water consumption of the intercropping system is often slightly different from sole cropping. They have conducted several experiments in which the seasonal rainfall varies from 84 to $575 \mathrm{~mm}$. They have finally concluded that the overall water consumption in the intercropping system is relatively higher than $7 \%$ compared to that in monoculture. Thus, the morphological and physiological differences between the two cultures in association (potato and sulla), allow them to occupy different soil depth. Similarly, the mechanisms by which the two intercrops are adapted to semi-arid environments did make interspecific facilitation (or complementarities) between these two species in water consumption (same reduction in water consumption for both intercrops). This explains that the AGDM production by the intercrop potato and sulla and the TUBDM production by potato were not affected by the intercropping system compared to sole cropping. This finding is similar to that of Cohen (1970) for both crops intercropped cowpea and sorghum. Intercropping potato with sulla improved WUE of potato and sulla in sole intercropping compared to sole cropping. These results are consistent with several researchers who have reported that the WUE in intercropping system was higher than in sole cropping (Reddy \& Willey, 1981; Morris \& Garrity, 1993; Mandal et al., 1996; 
Walker \& Ogindo, 2003). Similarly, it has been shown that the intercropping system potato-sulla had no impact on the total dry matter production by potato and by sulla in sole intercropping. This explains the improvement of the WUE in M3 and in M5. In fact, the increase in the WUE of the intercropping system can be explained by the elevated increase in total dry matter production with lowed increase in the total water consumption of the system. These results are in agreement with those of Black and Ong (2000). These authors have shown that the intercropping system can increase the proportion of water used for transpiration by a significant development of the canopy and reduced soil evaporation. This allows reducing the water consumption by crop in sole intercropping compared to sole cropping without affecting the total biomass production. Similarly, Karray (2006) reported that the study of certain types of intercropping showed an increase in the WUE of these crops compared to pure cultures without significant increase in consumption water.

Indeed, the proportion of transpiration flow in evapotranspiration is higher in intercropping than in monoculture. This led to the expansion of cover vegetation increases the intercropping system evapotranspiration and reduces the evaporation from the soil. Guvenc and Yildirim (1999) showed the benefits of intercropping systems in horticulture. These systems improved the efficiency of water use and land occupation. Other studies in intercropping system based on the dephasing of natural resources (water, fertilizers ...) peak demand for each culture showed the superiority of intercropping system productivity compared to monoculture (Hulugalle and Lal, 1986). Oluwasemire et al. (2002) found in intercropping system millet - cowpea that the WUE of millet in sole cropping was lower $\left(2.49 \mathrm{~kg} \mathrm{~m}^{-3}\right)$ than in the intercropping system $\left(2.89 \mathrm{~kg} \mathrm{~m}^{-3}\right)$. Similarly, Caviglia et al. (2004) found that the WUE of the intercropping system wheat-soybean was greater than $\left(3.12 \mathrm{~kg} \mathrm{~m}^{-3}\right)$ the soybean in sole cropping $\left(1.64 \mathrm{~kg} \mathrm{~m}^{-3}\right)$.The total LER for intercropping system potato-sulla was higher than one which confirmed the superiority of intercropping system over sole cropping.

\section{Conclusion}

Four main results were reached in this study. First, no differences in total dry matter production were found between potato and sulla in sole cropping and intercropping which means that the potato sulla intercropped increased the TDM of the intercropping system. Second, the intercrop potato and sulla consumed less water than in sole cropping but it had increased the total water consumption by the intercropping system. Third, potato and sulla in sole intercropping used water more efficiently and had greater WUE than in the sole cropping. Fourth, the total (LER) was higher than one, which indicates the superiority of intercropping system over the sole cropping system. In conclusion, Intercropping potato with sulla had no effect in the yield of potato in sole intercropping on one hand and on the other hand the intercropping system was generated a value of $50 \%$ of the cultivated area and also was allowed a additional forage production which ranged from 19.3 to $22.9 \mathrm{t} / \mathrm{ha}$. Therefore, this intercropping system was beneficial for the potato small grower.

\section{References}

Adiku, S. G. K., Ozier-Lafontaine, H., \& Bajazet, T. (2001). Patterns of root growth and water uptake of a maize-cowpea mixture grown under greenhouse conditions. Plant Soil, 235, 85-94. http://dx.doi.org/10.1023/A:1011847214706

Allen, R. G., Pereira, L. S., Raes, D., \& Smith, M. (1998). Crop evapotranspiration: guidelines for computing crop water requirements. FAO Irrigation and Drainage Paper 56 (p. 300).

Ati, A., Ammar, D. I., \& Salah, M. N. (2012). Water use efficiency of potato (Solanum tuberosum L.) under different irrigation methods and potassium fertilizer rates. Annals of Agricultural Sciences, 57, 99-103. http://dx.doi.org/10.1016/j.aoas.2012.08.002

Badr, M. A., El-Tohamy, W. A., \& Zaghloul, A. M. (2012). Yield and water use efficiency of potato grown under different irrigation and nitrogen levels in an arid region. Agricultural Water Management, 110, 9-15. http://dx.doi.org/10.1016/j.agwat.2012.03.008

Barhom, T. I. H. (2001). Studies on water requirements for some crops under different cropping systems. M.Sc. Thesis, Facility of Agriculture Cairo University.

Ben, J. F. (2005). Hedysarum coronarium L. Variation génétique, création variétale et utilisation dans les rotations tunisiennes. Thèse de doctorat en sciences biologiques appliquées. Université Gent/Belgique. Faculté des sciences en bioingénierie.

Bharati, V., Nandan, R., Kumar, V., \& Pandey, I. B. (2007). Effect of irrigation levels on yield, water-use efficiency and economics of winter maize (Zea mays)-based intercropping systems. Indian Journal of Agronomy, 52, 27-30. 
Black, C. R., \& Ong, C. K. (2000). Utilisation of light and water in tropical agriculture. Agric. For. Meteorol., 104, 25-47. http://dx.doi.org/10.1016/S0168-1923(00)00145-3

Bouwe, N. B., Walangululu, M., \& Kidanemariam, H. M. (2000). Performance de 4 cultivars de pomme de terre en culture associée avec le mais et le Haricot. Afr. Assoc. Conf. Proc., 5, 187-190.

Caviglia, O. P., Sadras, V. O., \& Andrade, F. H. (2004). Intensification of agriculture in the south-eastern Pampas I. Capture and efficiency in the use of water and radiation in double-cropped wheat-soybean. Field Crops Research, 87, 117-129. http://dx.doi.org/10.1016/j.fcr.2003.10.002

Cohen, D. (1970). The expected efficiency of water utilization in plants under different competition and selection regimes. Isr. J. Bot., 19, 50-54.

De Medeiros, G. A., Arruda, F. B., \& Sakai, E. (2005). Crop coefficient for irrigation beans derived using three reference evaporation methods. Agric. For. Meteorol, 115, $135-143$. http://dx.doi.org/10.1016/j.agrformet.2005.11.010

Fetene, M. (2003). Intra-and inter-specific competition between seedlings of Acacia etbaica and a perennial grass (Hyparrenia hirta). J. Arid Environ, 55, 441-451. http://dx.doi.org/10.1016/S0140-1963(03)00052-1

Gao, Y., Duan, A., Sun, J., Li, F., Liu, Z., Liu, H., \& Liu, Z. (2009). Crop coefficient and water-use efficiency of winter wheat-spring maize strip intercropping. Field Crops Research, 111, 65-73. http://dx.doi.org/10.1016/j.fcr.2008.10.007

Ghanbari, A., Dahmardeh, M, Siahsar, B. A., \& Ramroudi, M. (2010). Effect of maize (Zea mays L.) - cowpea (Vigna unguiculata L.) intercropping on light distribution, soil temperature and soil moisture in and environment. J Food Agr Environ, 8, 102-108.

Guvenc, I., \& Yildirim, E. (2005). Intercropping based on cauliflower more productive, profitable and highly sustainable. Europ.J. Agronomy, 22, 11-18. http://dx.doi.org/10.1016/j.eja.2003.11.003

Hauggaard-Nielsen, H., Ambus, P., \& Jensen, E. S. (2001). Interspecific competition, N use and intercropping with weed in pea-barley. Field crops Research, 70, 101-109. http://dx.doi.org/10.1016/S0378-4290(01)00126-5

Hillel, D. (1998). Environmental Soil Physics. London: Academics Press.

Hulugalle, N. R., \& Lal, R. (1986). Soil water balance of intercropped maize and cowpea grown in a tropical hydromorphic soil in Western Nigeria. Agron. J., $\quad 77, \quad 86-90$. http://dx.doi.org/10.2134/agronj1986.00021962007800010019x

Jabloun, M., \& Sahli, A. (2008). Evaluation of FAO-56 methodology for estimating reference evapotranspiration using limited climatic data Application to Tunisia. Agricultural water management, 95, 707-715. http://dx.doi.org/10.1016/j.agwat.2008.01.009

Kar, G., Kumar, A., Martha, M. (2007). Water use efficiency and crop coefficients of dry season oilseed crops. Agric. Water Manage, 87, 73-82. http://dx.doi.org/10.1016/j.agwat.2006.06.002

Karray, J. (2006). Bilan hydrique d'un système de cultures intercalaires (olivier- culture maraîchère) en Tunisie centrale : approche expérimentale et essai de modélisation. Ph.D. thesis, Ecole Nationale Supérieure Agronomique de Montpellier.

Li, L., Yang, S., Li, X., Zhang, F., \& Christie, P. (1999). Interspecific complementary and competitive interactions between intercropped maize and faba bean. Plant Soil, 212, $105-114$. http://dx.doi.org/10.1023/A:1004656205144

Mandal, B. K., Das, D., Saha, A., \& Mohasin, M. (1996). Yield advantage of wheat (Triticum aestivum) and chickpea (Cicer arietinum) under different spatial arrangements in intercropping. Indian J. Agron, 41(1), 17-21.

Morris, R. A., \& Garrity, D. P. (1993). Resource capture and utilization in intercropping water. Field Crops Res., 34, 303-317. http://dx.doi.org/10.1016/0378-4290(93)90119-8

Natarajan, M., \& Willey, R. W. (1980a). Sorghum-pigeonpea intercropping and the effects of plant population density. I. Growth and yield. J. Agric. Sci., Cambr, 95, 51-58. http://dx.doi.org/10.1017/S0021859600029269

Natarajan, M., \& Willey, R. W. (1980b). Sorghum-pigeonpea intercropping and the effects of plant population density. 2. Resource use. J. Agric. Sci., 95, 59-65. http://dx.doi.org/10.1017/S0021859600029270 
Ogindo H. O., \& Walker, S. (2005). Comparison of measured changes in seasonal soil water content by rained maize-bean intercrop and component cropping in semi arid region in South Phys. Chem. Earth, 30, $799-808$. http://dx.doi.org/10.1016/j.pce.2005.08.023

Oluwasemire, K. O., Stigter, C. J., Owonubi, J. J., \& Jagtap, S. S. (2002). Seasonal Water use and water productivity of millet-based cropping systems in the Nigerian savanna near Kano. Agricultural water management, 56, 207-227. http://dx.doi.org/10.1016/S0378-3774(02)00008-2

Reddy, M. S., \& Willey, R. W. (1981). Growth and resource use studies in an intercrop of pearl millet-groundnut. Field Crops Res., 4, 13-24. http://dx.doi.org/10.1016/0378-4290(81)90050-2

Rezig, M., Sahli, A., Jeddi, F. B., \& Harbaoui, Y. (2010). Adopting intercropping system for potatoes as practice on drought mitigation under Tunisian conditions. Options Mediterraneennes, 329-334.

Rodrigo, V. H. L., Stirling, C. M., Teklehaimanot, Z., \& Nugawela, A. (2001). Intercropping with banana to improve fractional interception and radiation-use efficiency of immature rubber plantations. Field Crops Res., 69, 237-249. http://dx.doi.org/10.1016/S0378-4290(00)00147-7

Sands, P. J., Hackett, C., \& Nix, H. A. (1979). A model of the development and bulking of potatoes (Solanum tuberosum L.). I. Derivation from well-managed field crops. Field Crops Res., 2, $309-331$. http://dx.doi.org/10.1016/0378-4290(79)90031-5

Sharaiha, R. K., Hadidi, N. A. (2008). Microenvironmental Effects on Potato and Bean Yields Grown Under Intercropping System. Lucrâri stiittifice, 51, 209-219.

Thorsted, M. D., Weiner, J., \& Olesen, J. E. (2006). Above- and below-ground competition between intercropped winter wheat Triticum aestivum and white clover Trifolium repens. J. Appl. Ecol., 43, $237-245$. http://dx.doi.org/10.1111/j.1365-2664.2006.01131.x

Tofinga, M. P., Paolini, R., \& Snaydon, R. W. (1993). A study of root and shoot interactions between cereals and peas in mixtures. J Agr Sci, 120, 13-24. http://dx.doi.org/10.1017/S0021859600073548

Vandermeer, J. H. (1992). The Ecology of Intercropping. New York, USA: Cambridge University Press.

Wahla, I. H., Ahmad, R., Ehsanullah, A. A., \& Jabbar, A. (2009). Competitive functions of components crops in some barley based intercropping systems. Int. J. Agric. Biol. (Pakistan), 11, 69-71.

Walker, S., \& Ogindo, H. O. (2003). The water budget of rainfed maize and bean intercrop. Phys. Chem. Earth, 28, 919-926. http://dx.doi.org/10.1016/j.pce.2003.08.018

Willey, R. W. (1990). Resource use in intercropping systems. Agric. Water Manage, 17, $215-231$. http://dx.doi.org/10.1016/0378-3774(90)90069-B

Yactayo, W., Ramírez, D. A., Gutiérrez, R., Mares, V., Posadas, A., \& Quiroz, R. (2013). Effect of partial root-zone drying irrigation timing on potato tuber yield and water use efficiency. Agric. Water Manage., 123, 65-70. http://dx.doi.org/10.1016/j.agwat.2013.03.009

\section{Copyrights}

Copyright for this article is retained by the author(s), with first publication rights granted to the journal.

This is an open-access article distributed under the terms and conditions of the Creative Commons Attribution license (http://creativecommons.org/licenses/by/3.0/). 